\title{
Water Sensitive Urban Design Tool
}

\section{Nouran Moustafa Mohamed \\ Teaching Assistant at Faculty of Regional \& \\ Urban Planning, Cairo university \\ nouranmoustafa@cu.edu.eg}

\section{Hesham El-Barmelgy}

Professor of Urban

Design \& Vice Dean of

Education \& Student

Affairs, Faculty of

Regional and Urban

Planning, Cairo university

\section{Marwah Sebaway Hamed}

Associate Professor of Urban Planning, Faculty of Regional and Urban Planning,

Cairo university
Noha Abd El-Aziz

Associate Professor of Urban Design, Faculty of Regional and Urban Planning,

Cairo university

\begin{abstract}
The 21st century is the century of City and Urbanization. As urban communities spread and populations grow, the impact on the natural environment escalates. The hydrological cycle is among the environmental aspects most impacted by urbanization. Consequently, this study suggests a "Water Sensitive Urban Design Tool" that comprises three dimensions: (i) determining the specific issues facing residential water demand; (ii) identifying the factors influencing these issues; and (iii) the relevant water sustainability objectives and criteria. The WSUD tool could be utilized by urban designers and planners to assess the water performance of residential urban areas. It could be employed to evaluate current conditions, suggested retrofitting options, or Greenfield developments. Thus, the tool not only measures the water sensitivity of residential areas but could also support decision-making and guide development. To evaluate the suggested WSUD tool and examine its suitability to the Egyptian context, particularly the residential sector, a survey was conducted with water-related experts and design specialists. Based on the survey a finalized version of the WSUD Tool was formalized.
\end{abstract}

Keywords: Water Sensitive Urban Design; Assessment Criteria; Water-related Sustainability Objectives; Drinking Water Sector.

\section{INTRODUCTION}

The 21st century is the century of City and Urbanization. The conventional Urban Water System (UWS) and its three main components: (1) water supply, (2) wastewater, and (3) stormwater have been considered the most important medical advance since 1840 (Larsen et al., 2016), and for most of the $20^{\text {th }}$ century water supply and sewerage authorities were the most effective urban planning agencies because development could not occur unless an area could be provided with a reliable supply of potable water (Troy \& Holloway, 2004). The entire world is suffering from water related challenges, a situation that is projected to soon turn from a pressing matter, to a world crisis threatening livelihoods, populations, as well as economies (WWAP, 2016).

Egypt is also already on the verge of a serious water issue, involving water quality as well as quantity. The country is rated as a region of elevated water quality risk (VEOLIA \& IFPRI, 2015). However, the actual concern lies in the tangible physical availability of water. A well-known indicator of national water scarcity is the annual per capita renewable water resources available. Figure (1 shows the decline in Egypt's per capita Available Renewable 
Water Resources, from $1893 \mathrm{~m}^{3} / \mathrm{cp} / \mathrm{yr}$ in 1960 to 1009 m³/cp/yr in 1990 putting Egypt at the edge of chronic water scarcity, then continuing to drop to reach $570 \mathrm{~m}^{3} / \mathrm{cp} / \mathrm{yr}$ by 2018. And according to future projections, Egypt's total renewable water resources will fall to $455 \mathrm{~m}^{3}$ per capita per year by the year 2030, placing its population in a state of absolute water scarcity (CAPMAS, 2014).

Figure (1) The Decline of Egypt's per capita Available Renewable Water Resources and the corresponding level of Water Scarcity.

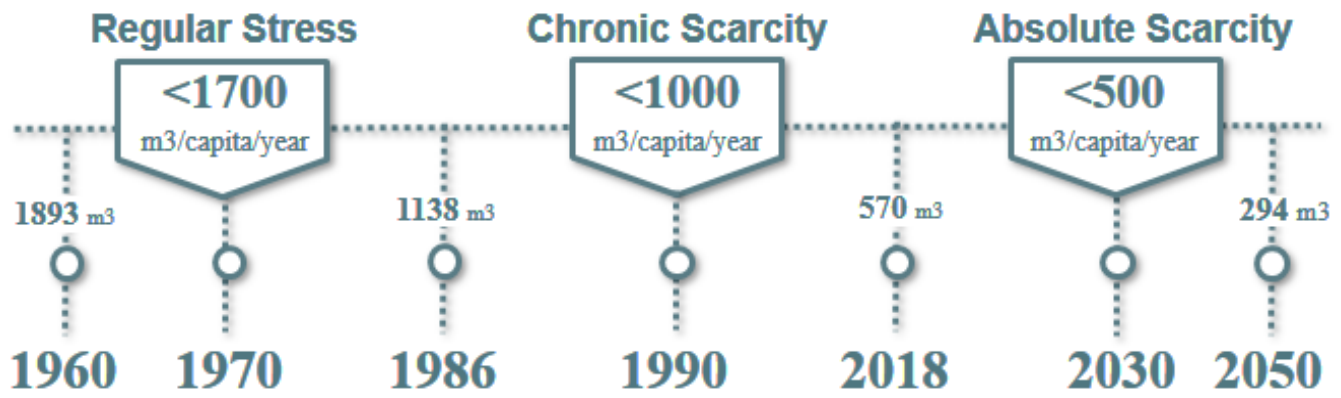

Source: Researcher based on data from CAPMAS, 2014.

Furthermore, Egypt's water balance for the year 2016-2017 indicated that the renewable water resources available from the river Nile, shallow groundwater aquifers and effective rainfall offers a total of 58.3 billion cubic meters annually, while the actual demand of the different sectors represented a total of 80 billion cubic meters for the same year. This designates a deficiency of 21.7 billion cubic meters, which was compensated for through wastewater recycling and reuse, extracting deep non-renewable groundwater and valley groundwater (CAPMAS, 2018).

As Egypt's urban communities spread and its population grow at alarming rates, the gap between water resources and demand will continue to widen. And the distressing effects of water scarcity are bound to halt development, disturb the economy, not to mention harm human health and well-being. Consequently, covering the water demands of the residential sector is particularly imperative, as it directly affects the daily life of all citizens. Furthermore, human health is considered a direct indicator of environmental stress in a region or city (Alberti, 1999). Human health issues can cause significant economic losses, including productivity losses and health treatment costs. This is particularly an issue in developing economies like Egypt, where urbanization seems to be driven by poverty rather than economic growth. A large proportion of the urban expansion in these areas is informal or slum settlements. These areas lack proper planning and in many occasions lack infrastructure services, which lead them to rely on stolen or illegal sources to satisfy their basic needs (UN-Habitat, 2008; GWP, 2011). 
Figure (2) The total water resources \& the total water demand for the year 2016-2017.

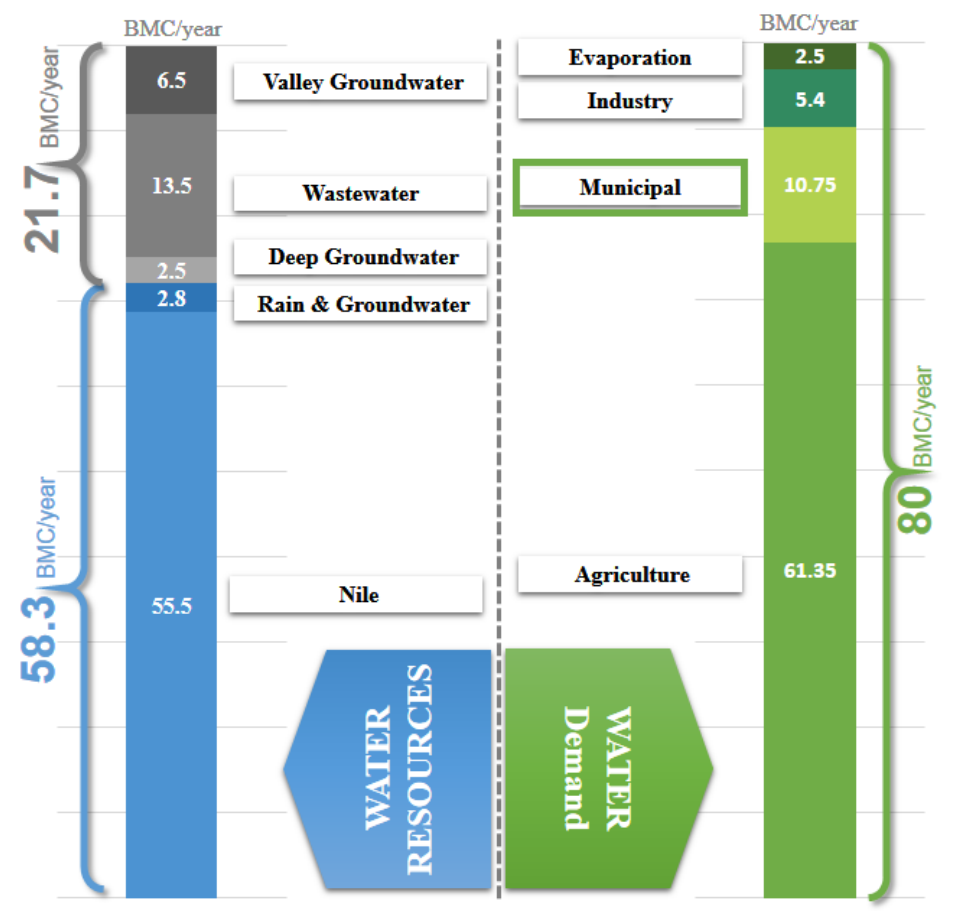

Figure (3) Municipal Water Demand in Egypt between 2002 and 2017.

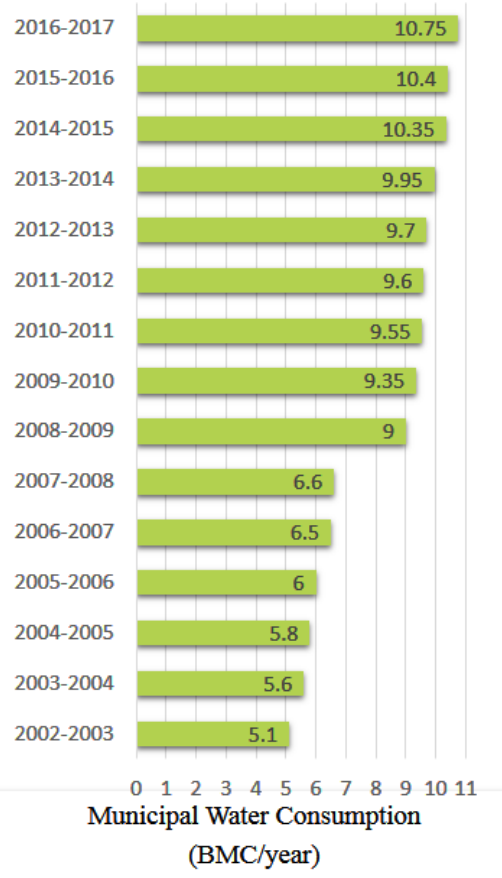

Source: Researcher based on data from CAPMAS, 2018.

The aim of this study is developing a tool that could help designers and planners assess the water sensitivity of urban residential areas by utilizing a set of water-related sustainability criteria. The tool is meant not only to help assess performance but also help identify points of weakness and guide decision making to ultimately ensure better integration of water in the design and planning of residential urban areas. The paper is divided into three sections: (i) exploring the Egyptian drinking water sector and factors influencing consumption; (ii) redefining water-related sustainability objectives and criteria; and (iii) assessing the effectiveness of the selected criteria through a survey conducted with professionals and researchers from the fields of water management and urban design.

\section{EGYPT'S DRINKING WATER SECTOR}

\subsection{Issues Facing the Sector}

Municipal water consumption has almost duplicated over the past decade, growing from 5.1 billion cubic meters in 2002-2003 to 10.75 billion cubic meters in 2016-2017 (Figure (3). The Residential Sector is the second largest consumer of water in Egypt (13.4\%), and the number one consumer of produced (drinking) water (63.4\%), making it the largest water consumer in urban areas. Egypt's drinking water sector faces various challenges. Firstly, the relevantly high percentage of non-revenue water. The national average of nonrevenue water is $29.7 \%$, and Cairo alone losses an estimate of $33.3 \%$ of its produced water (CAPMAS, 2017). The water losses could be divided into two categories: (i) 
Commercial losses and (ii) Natural losses. Commercial losses occur due to un-measured connections, errors in billings, stolen connections or loss in indoor connections. Natural losses occur due to leakages from the water network.

Secondly, the drinking water sector faces some economic concerns, since the cost recovery for maintenance and operation is estimated to be $80 \%$. This deficiency in cost recovery could be due to un-measured connections, un-collected billings, and relatively low water tariffs (EWRA, 2008). Additionally, a very critical issue that faces the drinking water sector is the relatively high average of per capita daily water consumption, which is estimated to be as high as 350 liters per capita per day. Wherase the World Health Organizatio (WHO) claim that the most basic domestic needs (including: drinking, showering, cooking, dish-washing, personal care) are estimated to be around 50 to 100 liters per person per day, excluding water for garden irrigation. Also in comparison to other countries, Egypt is among the highest regarding daily per capita residential water consumption (Figure (4).

Figure (4) Daily per capita residential Water Consumption for Egypt and other Countries.



Source: (EWRA, 2008).

\subsection{Factors Influencing Residential Water Consumption}

Many researchers (particularly in the field of planning) argue that urban development patterns affect the performance of environmental systems, although there is no general agreement on the exact manner or particular influence of these alternative patterns on the ecology (Alberti, 1996). Despite strong efforts to develop more resilient planning techniques, present planning still fail to determine how urban development might best be arranged to minimize negative impacts and create more favorable conditions (Troy et al., 2002). In order to understand the interactions between the urban environment and ecological processes, we need to consider that there are multiple factors and features working simultaneously and at various scales (Alberti, 1999b). These factors are all part 
of the overall urban ecosystem, which in turn comprise of multiple subsystems: social, economic, institutional, and ecological. And each of these subsystems is a complex entity of its own, affecting and being affected by the others at different structural and functional levels. An extensive review of water-related literature revealed a set of driving factors that could impact residential water consumption patterns. The driving factors could be categorized into: (i) biophysical and urban, (ii) socio-economic (Figure (5). There also environmental and climatic factors.

Figure (5) Factors Driving Residential Water Consumption Patterns.

\section{Biophysical Factors Factors}

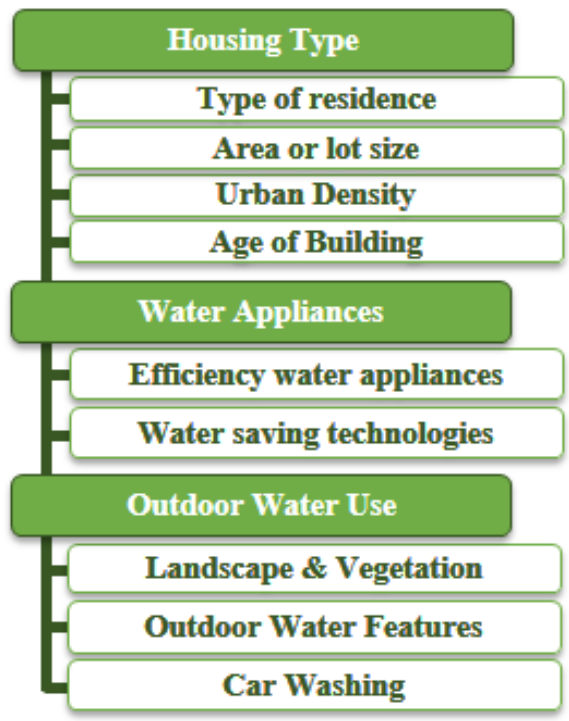

\section{Socio-Economic Factors}

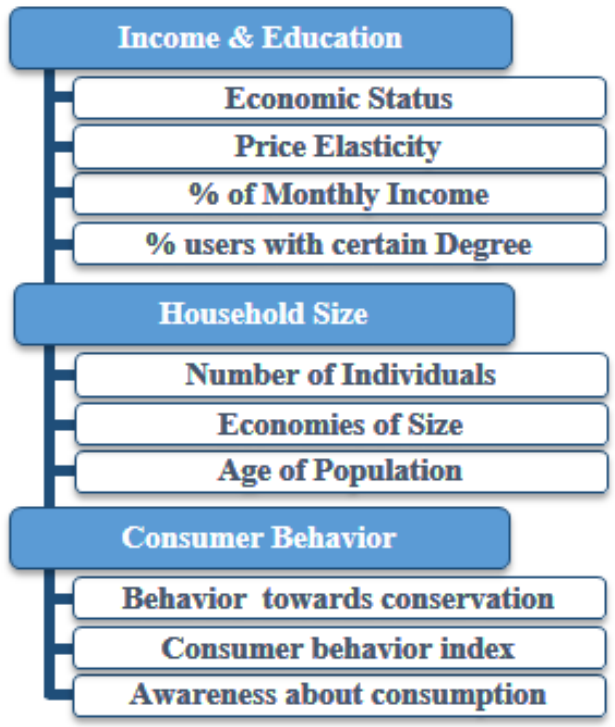

Source: Researcher

Biophysical and urban characteristics have recently been studied to define their impact on levels of household water use (Fox et al., 2009). Physical properties could include urban form, age of building, and material of construction, type of development and floor area of the building of each property, lot size, type of indoor appliances used and outdoor space. For example, research has shown that higher-density urban development reduces demand and lessens the costs of augmenting existing water infrastructure and supply (Balling et al., 2008). Relating to the variable building size, a study in the United Kingdom found significant differences between the water demanded during the peak summer months by properties with one bedroom vs. those with more (Fox et al., 2009). In Phoenix, Arizona, Guhathakurta and Gober (2007) found that for each 1,000 square foot increase in average lot size, water use increased by $1.8 \%$. Also, single houses with extensive outdoor water uses are major water consumers, and the consumption rate was noted to be positively correlated with garden size (Syme et al., 2004). Furthermore, the plantation species and type of landscaping also has a significant effect on water consumption, e.g. turf grass versus native of trees and shrubs in a Mediterranean climate (Domene et al., 2005). Additionally, when considering the age of the building on water consumption, it is usually argued that older dwellings have higher water consumption rates than more 
modern ones (Agthe \& Billings, 2002). Finally, from the literature review, three extensively analyzed UP metrics were identified: housing type, outdoor use and saving technologies.

The socio-economic characteristics include: income, household size, age, education and even the consumer's attitude and behavior. For example, the literature reveal a complex relation between income and residential water use (Balling, Gober, \& Jones, 2008). Many studies have proved, through strong empirical evidence, that water demand is rather inelastic in terms of income (e.g. Espey, et al., 1997; Dalhuisen, et al., 2003; Klein, et al., 2007; Worthington \& Hoffman, 2008). On the other hand, other studies have shown that residential water consumption tend to increase with income. Another factor, household size, could be a significant determinant of residential water consumption (e.g. Wentz and Gober, 2007; Schleich and Hillenbrand, 2009). As is expected, the overall water demand increase as the number of individuals increase in a household. However, the economies of size suggest the end result will be less water per capita in larger than in smaller households (Loh and Coghlan, 2003). Lastly, an interesting social factor to be considered is consumer behavior and attitude, especially towards conservation. According to some studies social cognitive theory recognizes human behavior as a dynamic interaction of the environment, personal factors, and behavior. Overall, human behavior is usually complicated and influenced by multiple factors many of which are not easily controlled (Sathyamurthi, 2013). For instance, some studies consider water use patterns to be more related to specific behaviors that are influenced by socio-demographic factors (income and household size) rather than to attitudinal factors (Gatersleben et al., 2002).

Environmental variables such as temperature, precipitation or drought and their temporal variation could have important influence on residential water consumption. Studies correlating water use to climate conditions focus on variations in time, rather than space. For example, some studies on the southwestern United States, have found significant relationships between temporal variations in water consumption and variations in climate (e.g. Gutzler and Nims, 2005). On the other hand, other studies found no link whatsoever (e.g., Gegax et al., 1998; Michelsen et al., 1999). This surprising diversity and contradictory conclusions was thought to be the result of multiple factors such as: differences in variables and methods used in the analysis, differences in the price of water, urban lifestyles, and the relative importance of outdoor versus indoor water use (Gutzler and Nims, 2005; Balling, et al., 2008).

The previous sections briefly demonstrated some of the hurdles facing the water sector in Egypt, and particularly the residential water sector, and then explored the factors that could influence the problem, particularly the residential consumption. The next logical step would be to identify possible strategies that could help overcome these issues and control their driving forces. However, there are countless forms of possible solutions, and to ensure best possible choices we should focus on potential benefits. Benefits could be translated in the form of design objectives and their corresponding indicators. Therefore, the next section explores the most appropriate water-related sustainability objectives, which could be used to assess current conditions and guide future developments. 


\section{Water Sustainability Objectives}

Tischner and Schmidt-Bleek (1993) argue that in order to create sustainable innovation in technology, we must not focus on the technology itself, but rather investigate the function or services provided by a given technology. There is a wide range of Water Sensitive Urban Design (WSUD) measures and technologies which can help improve the urban water cycle (Rozos \& Makropoulos, 2012). The wide variety of options available allow for well-tailored system that is perfectly fitted to a specific site or project (Speers \& Mitchell, 2000). The decision making process is influenced by diverse interests, conflicting demands and even limiting constraints. Therefore, it is all about balancing objectives and recognizing assessment criteria (Global Water Partnership, 2011). The proper set of criteria could help assess the performance of any system (sustainability of water management in this case), as well as support decision making and future designs. So that solutions could then be combined into packages and ranked according to the specially identified criteria (Grit, Jo“rg, Steffen, \& Osor, 2014).

The traditional water management approach has a rigorous set of goals: (1) ensure access to water and sanitation; (2) manage wastewater; (3) manage rainwater and stormwater drainage; (4) control waterborne diseases and epidemics; (5) and reduce the risk of waterrelated hazards, including floods, droughts, and landslides (Global Water Partnership, 2011). Although these goals seem rightfully virtuous, they alone have failed in sustaining a resilient service and a healthy ecosystem; as reviewed in the first chapter. Water can no longer be thought of as simply another component of nature that needs to be "controlled". Therefore, a new more comprehensive set of goals are required to ensure a more effectual close to nature urban water system. Setting the right set of goals and objectives is an important part of any decision-making process and is essential to achieve the maximum levels of success for any sustainable development course. The selection of technologies and solutions and the overall design of the UWS will heavily depend on the identified objectives (Sharma, et al., 2009).

The term "objectives" is often used to convey an exact and measurable desired outcome. Consequently, the ultimate goal would be to raise the sustainability profile of the urban water system, or at least decrease its un-sustainability level. Numerous efforts were exerted by international agencies, national governments and development agencies to identify water-related development goals and objectives. Therefore, it comes as no surprise that most of these goals have been recognized by world nations and agreed on, since water is a global resource that is connected on the worldwide level. There are various examples of these global acts and agendas, as well as comprehensive indices utilized to assess water sustainability of cities and communities.

Water sustainability objectives explored in this study were derived from two types of sources: (i) global and international sustainability agendas, and (ii) water sustainability assessment indices (Table (1). The sustainability agendas displayed more general description of desired outcomes or favorable conditions in the form of design/planning objectives. Whereas, the indices offered more specific and above all measurable assessment variables, which were also based on the vision of "what should be". Overall, 
reviewing these agendas and indices uncovered a shared set of water-related sustainability objectives that guided them, although at varying degrees. The mutual objectives were categorized under six overarching goals: (i) Ecosystem; (ii) Urban Water System (UWS); (iii) Social; (iv) Economic; (v) Resilience; and (vi) Urban \& Place Making goals. Each goal encompasses a number of design objectives, giving a total of 13 waterrelated sustainability objectives. The progress towards achieving those objectives is assessed through a set of assessment criteria.

Table ( 2 demonstrates the collective findings of the review of the agendas and indices. Although each source offered a somewhat unique description of its objectives, the final descriptions established in Table ( 2 offers the common underlying ideas behind each objective. The review revealed that ecosystem-related goals are the most commonly comprehended by all sources, probably since it directly addresses the negative impacts of UWS on environmental performance. Secondly, the social objective concerned with ensuring adequate and equitable access to water and sanitation services is specifically addressed in almost all sources. This is logical, since service provision is the major goal of even the conventional UWS. Moreover, it is also important to note that UWS objectives were recognized by various sources, especially water use efficiency and balancing multiple functions. Additionally, economic and resiliency objectives were acknowledged by almost $50 \%$ of the sources. Finally, design and place making objectives came in final place and were not given high priority.

Consequently, this study suggests a "Water Sensitive Urban Design Tool" that comprises three dimensions: (i) the specific issues facing residential water demand; (ii) the factors influencing these issues; and (iii) the associated water sustainability objectives and criteria. The WSUD tool could be utilized by urban designers and planners to assess the water performance of residential urban areas. It could be employed to evaluate current conditions, suggested retrofitting options or Greenfield developments. Thus, the tool not only measures water sensitivity of residential areas, but could also support decision making and guide development. This could be established by correlating the prioritized sustainability objectives with the potential benefits offered by the various solutions and strategies. In order to evaluate the suggested WSUD tool and examine its suitability to the Egyptian context, particularly the residential sector, a survey was conducted. The survey covers the three dimension of the WSUD Tool. 
Table (1) Sustainability Agendas \& Indices reviewed for this study.

\section{Agenda 21:}

Developed by the UN during its Conference on Environment and Development (UNCED) held in Rio de Janeiro in 1992. Water related goals were set in chapter (18) of the conference's 'Agenda 21', titled "Protection of the quality and supply of freshwater Resources: application of integrated approaches to the Development, management and use of water resources".

The Millennium Development Goals (MDGs)

Developed by the UN during the Millennium Summit in September 2000. The MDGs represented a benchmark towards results-based approach, which highlights the need to quantify results. MDG 7, is related to 'Environmental Sustainability' in general, and has three targets specifically related to water resources.

The European Union Water Framework Directive (EUWFD)

Developed by the European Union as a framework for community action in the field of water policy. The general aim of the EUWFD is to establish a framework in which to protect inland surface waters, transitional waters, coastal waters and groundwater.

The World Water Council (WWC)

The WWC was created in 1996 in response to the growing concern from the global community about worldwide water issues.

Sustainable Development Goals (SDGs)

The '2030 Agenda' for Sustainable Development was set by the UN in September 2015. It is one of the most recent, and comprehensive acts. SDG 6 focus on 'Clean Water \& Sanitation' and seeks to ensure availability and sustainable management of water and sanitation for all'.

\section{Egypt Vision 2030}

Pursues a more competitive, balanced and diversified future for Egypt. The 2030 vision encompasses three major strategic goals: (i) economic, (ii) social and (iii) environmental dimension. The vision incorporates some water-related sustainability goals that particularly fall under the environment dimension.

Water Sensitive Cities Index (WSCI)

WSCl was developed by the CRC for Water Sensitive Cities to assess and compare cities based on their water sensitivity performance. The index intends to support planners and decision makers evaluate their cities' urban water management courses.

\section{City Blueprint}

The City Blueprint is a baseline assessment of the sustainability of water management in a municipality (or other dominantly urban region). It allows a city to quickly understand how advanced it is in sustainable water management and to compare its status with other cities.

Water Poverty Index (WPI)

WPI is holistic water management tool. It syndicates data on water resources, access, use, social and economic capacity and water related environmental quality to the provision of the water at the community, national, basin, and region level.

Watershed Sustainability Index (WSI)

The WSI is a watershed specific index that takes into account cause-effect relationships and considers policy responses implemented in a given period. The WSI integrates the Hydrology $(H)$, Environment $(E)$, Life $(L)$ and Policy $(P)$ aspects of a watershed under three parameters: Pressure, State and Response.

Sustainable Cities Water Index (SCWI)

The SCWI was developed by Arcadis (global design and consultancy firm) to analyze water management. It investigates water sustainability in three core elements: (a/resiliency) ability to withstand natural disasters and unforeseen shortages; (b/efficiency) effectively manage the water supply; (c/quality) provision of clean and healthy water supply.

Source: Researcher. 
Table (2) Water-related Sustainability Objectives \& Criteria.

\begin{tabular}{|c|c|c|c|c|}
\hline $\begin{array}{l}\frac{n}{\pi} \\
\text { o } \\
\frac{c}{0} \\
\sum\end{array}$ & & $\begin{array}{l}\text { Design } \\
\text { Objectives }\end{array}$ & Assessment Criteria & 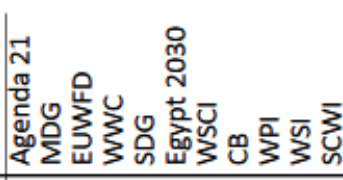 \\
\hline \multirow{4}{*}{ हूँّ } & \multirow[t]{2}{*}{01} & \multirow[t]{2}{*}{$\begin{array}{l}\text { Protect Water } \\
\text { Quality }\end{array}$} & $\begin{array}{l}\text { Eliminate \& minimize release of hazardous chemicals \& } \\
\text { materials. }\end{array}$ & \multirow{2}{*}{$\bullet \bullet \bullet \bullet \bullet \bullet \bullet \bullet \bullet$} \\
\hline & & & Reduce the proportion of untreated wastewater. & \\
\hline & \multirow[t]{2}{*}{02} & \multirow{2}{*}{$\begin{array}{l}\text { Protect Water } \\
\text { Availability }\end{array}$} & Ensure sustainable water withdrawals. & \multirow{2}{*}{$\bullet \bullet \bullet \bullet \bullet \bullet \bullet$} \\
\hline & & & Assess \& enhance the efficiency of virtual water trading. & \\
\hline \multirow[t]{2}{*}{ - } & \multirow[t]{2}{*}{03} & \multirow{2}{*}{$\begin{array}{l}\text { Protect Eco- } \\
\text { system Health }\end{array}$} & Protect areas of high ecological value. & \multirow{2}{*}{$\cdots \cdots \bullet$} \\
\hline & & & Protect \& restore natural habitats \& bio-diversity & \\
\hline \multirow{10}{*}{ 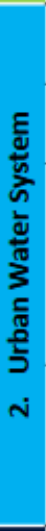 } & 04 & $\begin{array}{l}\text { Demand } \\
\text { Management }\end{array}$ & $\begin{array}{l}\text { Reduce water demand \& eliminate unsustainable } \\
\text { consumption patterns. }\end{array}$ & $\bullet \bullet \bullet \bullet \bullet \bullet \bullet$ \\
\hline & 05 & $\begin{array}{l}\text { Resource } \\
\text { Efficiency }\end{array}$ & $\begin{array}{l}\text { Raise water-related energy/nutrient efficiency \& recover } \\
\text { energy/nutrients where possible }\end{array}$ & $\bullet \bullet$ \\
\hline & \multirow[t]{4}{*}{06} & \multirow{4}{*}{$\begin{array}{l}\text { Build Technical } \\
\text { Capacity }\end{array}$} & Reduce system loss and leakage from network. & $\bullet$ \\
\hline & & & Use durable system components. & \multirow{2}{*}{$\bullet \bullet$} \\
\hline & & & Ensure adequate maintenance of system components. & \\
\hline & & & $\begin{array}{l}\text { Improve and expand monitoring, data management, and } \\
\text { analysis to support decision-making }\end{array}$ & $\bullet \bullet$ \\
\hline & \multirow[t]{4}{*}{07} & \multirow{4}{*}{$\begin{array}{l}\text { Build } \\
\text { Institutional } \\
\text { Capacity }\end{array}$} & Enhance knowledge, skill \& organizational capacity. & \multirow{2}{*}{$\bullet \bullet \bullet$} \\
\hline & & & Promote a dynamic, interactive \& multi-sectoral management & \\
\hline & & & Prepare and enforce water-related laws \& regulations. & $\bullet \bullet$ \\
\hline & & & Promote transboundary cooperation as appropriate. & $\bullet$ \\
\hline \multirow{5}{*}{ त्ञू̆ } & \multirow[t]{2}{*}{08} & \multirow{2}{*}{$\begin{array}{l}\text { Ensure Service } \\
\text { Provision }\end{array}$} & Provide safe \& continuous water \& sanitation services. & \multirow{2}{*}{$\bullet \bullet \bullet \bullet \bullet \bullet \bullet \bullet \bullet$} \\
\hline & & & Ensure equity \& affordability to the entire community. & \\
\hline & \multirow[t]{3}{*}{09} & \multirow{3}{*}{$\begin{array}{l}\text { Build Social } \\
\text { Capital }\end{array}$} & Promoting public engagement, participation and transparency & \multirow{3}{*}{$\bullet \bullet \bullet \bullet \bullet$} \\
\hline & & & Raise awareness about basic healthy and hygienic behaviour. & \\
\hline & & & $\begin{array}{l}\text { Ensure acceptability of users \& stakeholders to the water } \\
\text { management plans \& solutions. }\end{array}$ & \\
\hline \multirow{2}{*}{ 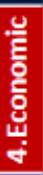 } & \multirow[t]{2}{*}{10} & \multirow[t]{2}{*}{ Cost Recovery } & $\begin{array}{l}\text { Ensure cost recovery of water services to cover operation, } \\
\text { maintenance, marginal, average and total cost categories. }\end{array}$ & \multirow{2}{*}{$\bullet \bullet \bullet \bullet \bullet$} \\
\hline & & & Protect the system against financial risks. & \\
\hline \multirow{4}{*}{ 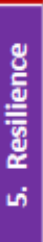 } & 11 & Enhance & Achieve self-sufficiency through reuse, recover, recycle. & \\
\hline & & System & Lower external water dependency ratio. & \\
\hline & & Flexibility & $\begin{array}{l}\text { Quantify the impact of climate change on freshwater } \\
\text { resources. }\end{array}$ & \\
\hline & & & $\begin{array}{l}\text { Mitigation \& Adaptation plans to droughts/floods \& extreme } \\
\text { events. }\end{array}$ & $\bullet \bullet$ \\
\hline & 12 & $\begin{array}{l}\text { Integrated } \\
\text { Planning }\end{array}$ & $\begin{array}{l}\text { Integrate the natural \& urban water into the different } \\
\text { planning phases. }\end{array}$ & $\bullet \bullet$ \\
\hline 赵 & 13 & Place Making & $\begin{array}{l}\text { Integrate water into the landscape \& ensure quality urban } \\
\text { spaces. }\end{array}$ & \\
\hline 起 & & & Mitigate negative effects of urbanization. & \\
\hline ம & & & $\begin{array}{l}\text { Improve aesthetic \& recreational appeal \& strong sense of } \\
\text { identity. }\end{array}$ & \\
\hline & & & Ensure equitable \& affordable access to amenity values & $\bullet \bullet \bullet$ \\
\hline & & & Raise the available per capita outdoor green space. & \\
\hline
\end{tabular}

Source: Researcher. 


\section{Survey}

This section displays the results of a field survey to explore the opinion of water-related experts, planners and designers on the suggested tool. The aim of the survey was to verify the most relevant water issues facing the residential sector, confirm the most significant factors influencing the problems and finally, identify the chief water sustainability objectives and criteria and their suitability to the Egyptian residential context.

\subsection{Types of Tools Applied in the Survey}

Two types of tools were applied in the field study in order to explore the opinions of water and design related experts and professionals concerning the model suggested to assess the water sensitivity of residential areas. The first tool was a questionnaire form that was extensively detailed. This form mainly targeted researchers, experts and practitioners in the fields of water hydrology and hydraulics. The second tool was an online survey which was a briefer and updated version of the questioner to make it more convenient for the respondents. The online survey mainly targeted researchers and practitioners in the fields of architecture and urban design, but also involved a number of water-related practitioners.

\subsection{Sampling Strategy}

In order to maximize the comprehensiveness of the results and achieve the goals of the survey, two main groups of respondents were determined: (i) water-related experts and (ii) design experts. The water-related experts included researchers and practitioners in the fields of water hydrology ${ }^{1}$ and water hydraulics ${ }^{2}$. This included researchers from the National Water Research Center (NWRC) and its affiliated institutes, such as Drainage Research Institute and Nile Research Institute. The questionnaire was also conducted with field practitioners and engineers specialized in the design, supervision and implementation of water, drainage, irrigation and firefighting networks on the scale of buildings and larger projects. And finally, engineers from the Holding Company for Water and Waste Water (HCWW).

Secondly, the design experts involved researchers and practitioners in the fields of architecture, urban design and urban planning. This comprised research experts in the fields of architecture and urban design from Cairo University and Ain-Shams University. The practitioners included those working in the private sector, as well as some with backgrounds in development projects.

\subsection{The Questionnaire Design}

The questionnaire starts off with a summary about the study being conducted and a statement of the survey goals. The survey was divided into three main sections. The first

\footnotetext{
${ }^{1}$ Hydrology: A topic in the fields of geology, civil and environmental engineering, concerned with the study of water quality, movement and distribution.

${ }^{2}$ Hydraulics: A topic in the fields of applied science and engineering dealing with the mechanical properties of liquids and covers concepts such as pipe flow, dam design, pumps, hydropower, flow measurement, river channel behavior and erosion.
} 
section aimed to identify the most common water issues within the residential sector. The second section involved the factors that could influence the performance of the urban water cycle (UWC), and thus should be extensively studies. The final section explored the degree of significance and relevance of the sustainability criteria in assessing the performance of the Egyptian UWC, particularly in residential areas.

The Influencing Factors section explored the factors that are likely to influence residential water consumption and thus are important to assess. This included two types of factors: (i) socio-economic and (ii) biophysical factors. The biophysical factors comprised natural factors (e.g. the natural water cycle, available water resources, and climatic characteristics) and manmade factors (e.g. elements of the urban water system, energy and nutrients consumption, urban characteristics). As for the socio-economic factors, these included water pricing, average family income, educational level, and consumer behavior. The respondents were asked (based on their practical expertise and acquired knowledge) to identify the degree of significance of each of the above-mentioned factors, on the performance of the UWC in residential areas.

The third section of the survey explored the relevance and applicability of the aforementioned water sustainability objectives. The respondents were asked to rate each sustainability objective based on their importance and relevance to the Egyptian residential context. The section surveyed the thirteen previously identified sustainability objectives. However, an objective specifically measuring the "affordability" of water services was added within the economic goal. This was proposed to consolidate with "cost recovery", which sometimes encourages the involvement of the private sector, and thus requires additional emphasis on the importance of economic accessibility of water services.

The questions used in the survey were rating scale questions with three variation degrees (1-weak/no; 2-moderate; 3-Strong). After Each section there was an open ended question to compensate for the high rigidity of the rating scale questions and allow the respondents higher degree of freedom. As for the online survey, it also comprised the same main sections as the questionnaire. However, some of the questions were merged when proper, to make it more appropriate and less time consuming for the respondents.

\section{RESULTS \& DISCUSSION}

The data from the questionnaire and the online survey was collected, categorized and analyzed.

\subsection{Water issues in the residential sector}

The first section explored the most frequent water issues in the residential sector based on the respondents' professional experience and backgrounds. Five main issues were tested and liberty was given to the respondents to add other suggestions. Figure (6 displays the results of the data analysis while demonstrating the choices made by practitioner and researchers in the fields of hydrology and hydraulics, designers and finally the overall average. 
Figure (6) The most frequent water issues in the residential sector based on the respondents' experience.

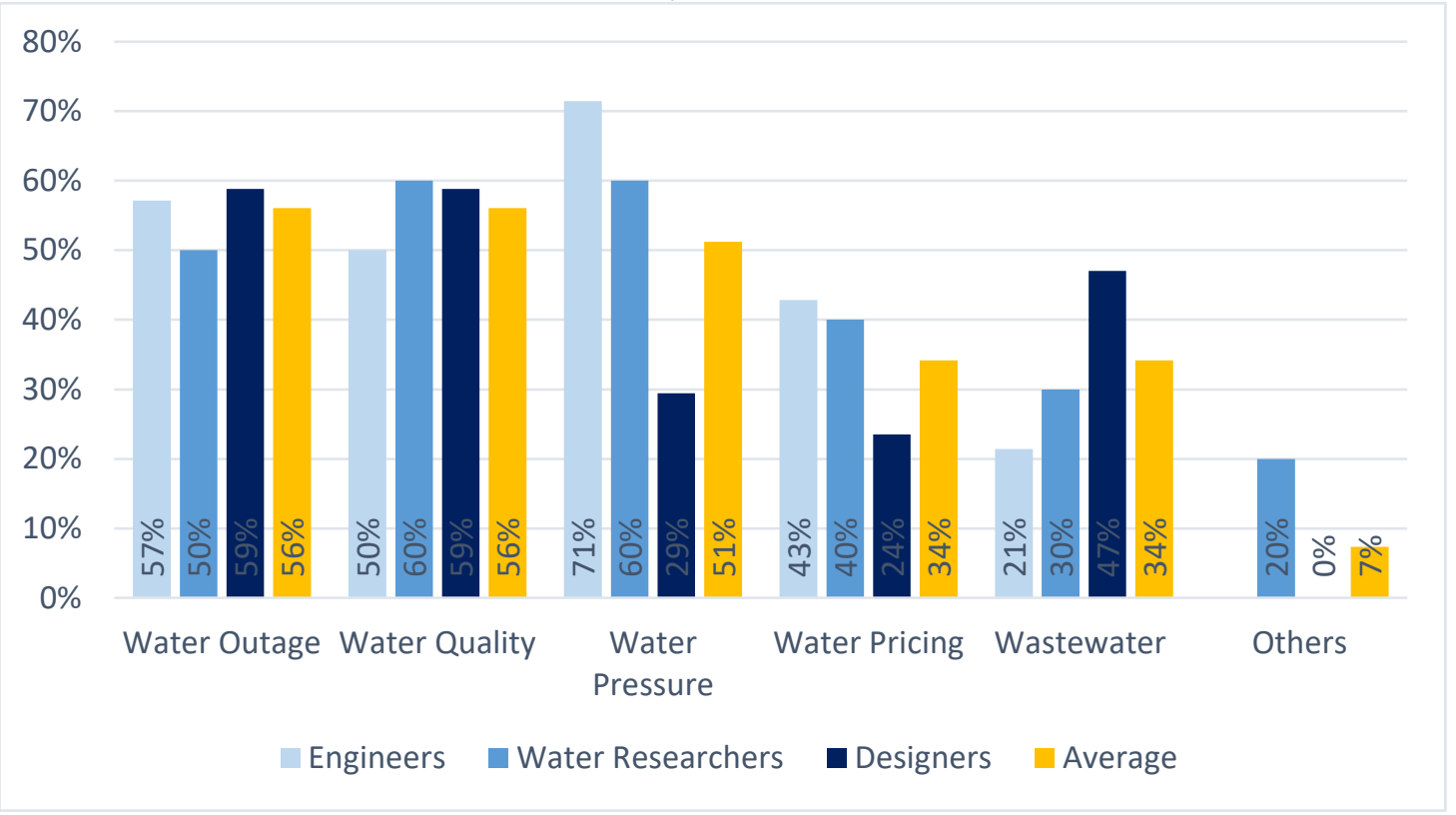

The results indicate that water outage and water quality issues are the most common in the residential sector. According to respondents water outage could be the result of temporary issues in the distribution networks such as breaks in the pipes, but could also happen due to more grave issues such as insufficient water quantities or pressure, especially in new residential areas.

Issues with water pressure came in third place when considering the total average. However, it was considered the most important issue by civil engineers and researchers, while only $29 \%$ of designers considered it a problem. It could be assumed that the opinion provided by the engineers and researchers groups is more significant concerning this particular issue, since water pressure is a hydraulics topic and thus, lies within their direct field of expertise and knowledge.

Water pricing scored an average of $34 \%$, with higher rating for engineers and researchers (43\% and $40 \%$ respectively). The respondents suggested the issue was mainly due to high water tariffs, but it was also suggested that there was problems with the billing system. This included problems with water meters that were inefficient or not working at all. Furthermore, there are problems with the agents responsible for collecting water readings and bills.

Wastewater also scored an average of $34 \%$, with the designers being the highest rating group for this subject. However only $21 \%$ and $30 \%$ of engineers and researchers, respectively considered the presence of frequent issues with wastewater. Finally, other issues stressed by the respondents included the lack of awareness of residential water users and their relatively high water consumption patterns. 


\subsection{Factors Driving Consumption}

The next section of the survey explores the degree of influence of some factors on the performance of the Urban Water Cycle and thus, the significance of reviewing them when dealing with residential water consumption. The factors explored included the Natural Water Cycle (NWC), Available Water Resources, Main Urban Water System (UWS), Sub UWS, Urban, Economic, Social and Environmental Characteristics. Figure ( 7 displays the findings of this section. Firstly, $75 \%$ of the respondents considered the UWS to be a strong influencing factor and $21 \%$ considered it to have moderate influence; making the UWS the factor with highest rating among respondents. The efficiency of the distribution network was given highest priority, followed by water treatment methods and technologies.

Secondly, urban and economic characteristics were considered by $66 \%$ and $60 \%$ (respectively) of respondents to be strong influencing factors, while $27 \%$ and $30 \%$ considered them to have moderate influence, respectively. Specifically the type of residence, built density and pricing system were deemed most significant.

Thirdly, the Sub-UWSs and social characteristics, both had relatively close results, where $44 \%$ and $51 \%$ of respondents considered them to be strong influencing factors, respectively. However, results suggest that education level and consumer behavior are the most influential. Finally, the NWC and environmental characteristics were rated by $44 \%$ and $37 \%$ (respectively) of respondents to be strong influencing factors, while $42 \%$ and $38 \%$ (respectively) considered them to have moderate influence.

Figure (7) The degree of influence of some factors on the performance of the Urban WaterCycle.

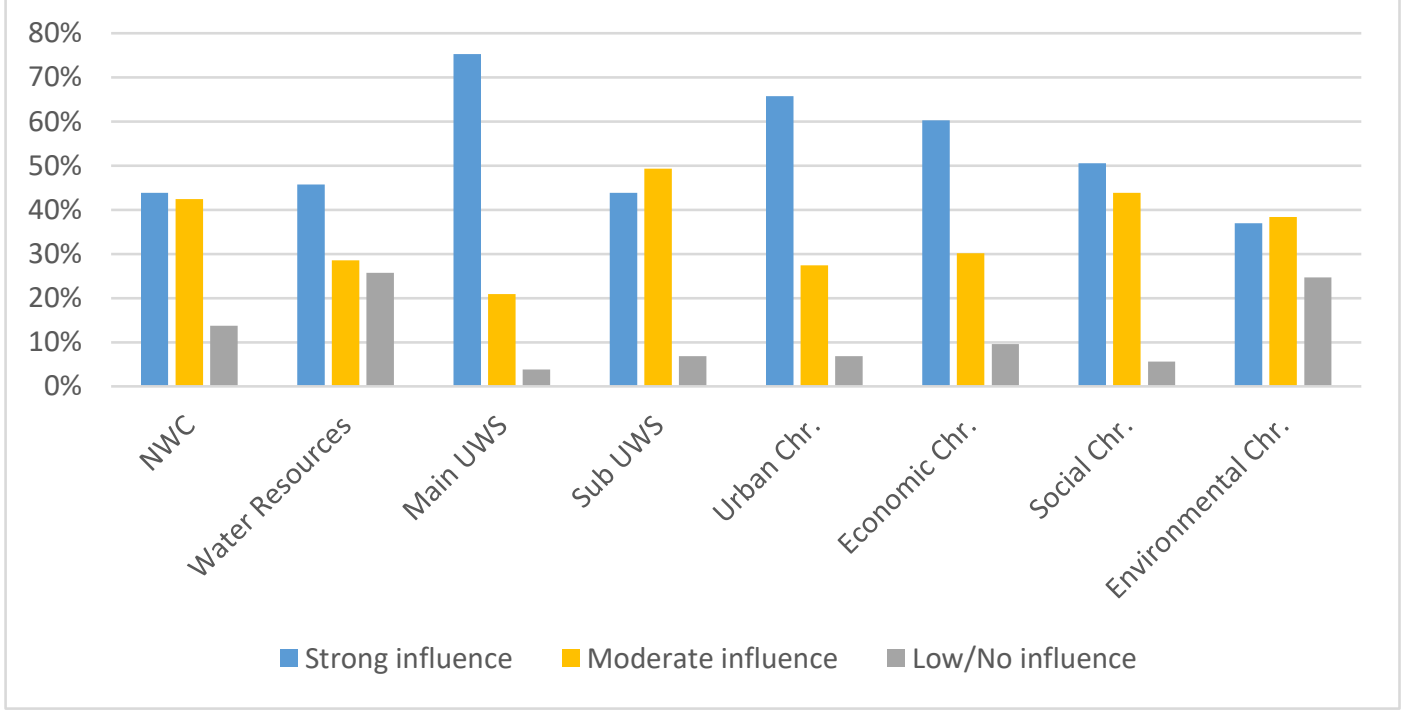

\subsection{Water-Related Sustainability Objectives}

The final section explores the importance of water related sustainability objectives (Figure (8). According to the survey results, service provision was given high priority by $86 \%$ of respondents, directly followed by water quality with $84 \%$ of respondents rating it as highly important. Next, demand management and protecting water resources from 
depletion were rated to be highly important by $73 \%$ and $71 \%$ of the respondents, respectively. Moreover, building effective technical and institutional capacity were also regarded by the majority of the respondents to be of high importance $(68 \%$ and $71 \%$ respectively). Although, some respondents pointed that institutional capacity is mainly the responsibility of the government. Likewise, economic objectives were had also relatively high rating, with affordability and cost recovery rated highly important by $68 \%$ and $66 \%$ of respondents, respectively. Furthermore, proper integration of water management into design and planning was graded highly by $66 \%$, and $32 \%$ considered it to be of moderate significance.

Environmental objectives had relatively average ratings; ecosystem protection were rated $37 \%$ high and 54 moderate. Whereas, water-related resource efficiency were regarded by $48 \%$ as high and by another $48 \%$ as moderate. The social objective public participation was also in the middle category, with $42 \%$ rating it as highly important and $47 \%$ rating it moderate. In addition, system flexibility and resilience to change was regarded by $45 \%$ and $36 \%$ of respondents as highly and moderately significant, whereas, the remaining $19 \%$ considered it to be of no importance. Finally, in last place was urban spaces quality and improving aesthetics, with scores of $32 \%$ high, $44 \%$ moderate and $25 \%$ no importance.

Figure (8) The degree of significance of water-related sustainability objectives according to the respondents.

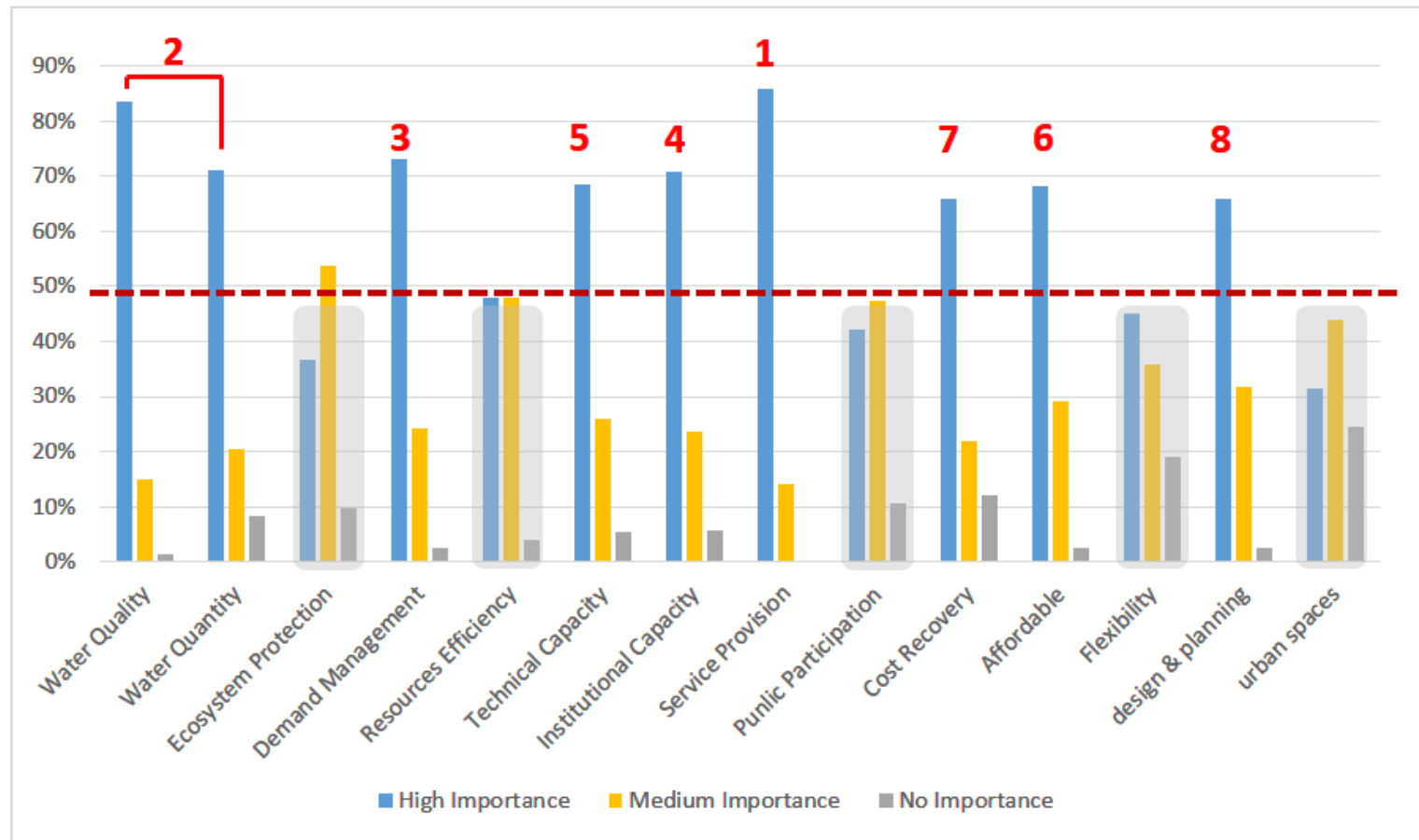

\subsection{Final Model}

Based on the findings of the survey eight water-related sustainability objectives were found to constitute the highest degree of significance and therefore, were selected for adoption within the WSUD Tool. Firstly, service provision, which is the most basic goal for UWSs. Secondly, water quality and quantity will be merged into one objective under the 
term water availability. Thirdly, demand management to secure resources to cover the rising requirements for development and the growing population. Additionally, institutional capacity means building knowledge, skill and promoting dynamic and interactive multi-sectoral management to reinforce WSUD. Also, technical capacity cover system durability, operation, appropriate maintenance, as well as monitoring and data collection. Moreover, cost recovery is crucial for system sustainability and might require involvement of the private sector. In this sense, it is vital to consider the affordability of the service, since water is not a simple commodity but a human right. Finally, design and planning objectives support the overall integrity of the built environment, and enhance urban space quality.

\section{CONCLUSION}

In conclusion, the water problem is threatening global and local communities, thus requiring a swift and robust approach. With various new approaches emerging from different parts of the world, calling for more sustainable and sensitive water management, urban designers and planners must assume their responsibility. This study suggests a tool to assess the water sensitivity of urban residential areas, as well as support decision making.

The suggested WSUD Tool encompasses three dimension: (i) specific water issues, (ii) influencing forces and (iii) sustainability objectives and criteria. The selected assessment criteria should directly address the local context's specific issues and characteristics. In order to assess the suitability of the tool for the Egyptian residential context a survey was conducted with 41 researchers and professionals in the field of water and development. The first section of the survey inspected the most common water related issues facing the residential sector. And it was suggested to be water quality, outage and pressure are the most common problems. Whereas, water pricing and wastewater management were condemned troublesome by less than $50 \%$ of the respondents.

The second dimension of the WSUD Tool explores the factors influencing the performance of the UWC and particularly residential water consumption (which reached $350 \mathrm{l} / \mathrm{cap} /$ day). The study suggested that urban characteristics is one of the most important factors influencing water consumption patterns, especially urban density and housing type. Although, demographic characteristics, such as education level or household size were considered insignificant, however, user behavior was suggested to be of very high significance.

Finally, due to the high complexity of the subject of water, the third dimension of the WSUD encompasses setting sustainability objectives and criteria. By reviewing global sustainability agendas and assessment indices it was possible to identify the most commonly pursued water-related sustainability objectives. These objectives were also reviewed in the survey to define their relevance to the Egyptian case. The provision of adequate, affordable and equitable water and sanitation service was given highest priority, along with protecting water quality and quantity and managing demand. Furthermore, raising the technical efficiency of the water system, especially regular 
maintenance and monitoring was also considered very important. Nonetheless, integrating water into the landscape to enhance the quality of urban spaces or help mitigate the impact of climate change was found to be the least important design objective.

All in all, the WSUD Tool suggested by this study could be further refined as more detailed studies are conducted within each of the three main steps. The Model was intended to be flexible and resilient, to not only accept changes as new data appears, but to better fit whatever case or context it is applied to.

\section{References}

Agthe, D. \& Billings, B. (2002). Water price influence on apartment complex water use. Journal of Water Resources Planning and Management, 128(5), 366-369.

Alberti, M. (1999). Urban Patterns and Environmental Performance : What Do We Know ? Journal of Planning Education and Research, 19, 151-163.

Alberti, M. (1999b) Modeling the urban ecosystem: A conceptual framework. Environment and Planning B: Planning and Design 26, 605-630.

Alberti, M. (1996). Measuring urban sustainability. Environmental Impact Assessment Review. 16(4-6), 381-424

Balling, R. C. J., Gober, P., \& Jones, N. (2008). Sensitivity of residential water consumption to variations in climate: An intraurban analysis of Phoenix, Arizona. WATER RESOURCES RESEARCH, 44, 1-11.

CAPMAS. (2014). Water Resources in Egypt and rationalization of consumption. Cairo.

CAPMAS. (2017). Annual Report for the Drinking Water and Wastewater Statistics for the year 2015/2016. Cairo, Egypt.

CAPMAS. (2018). Statistical Yearbook-Environment. In Statistical Yearbook (p. 18). Cairo: CAPMAS.

Dalhuisen, J.M., Florax, R.J.G.M., de Groot, H., Nijkamp, P. (2003). Price and income elasticities of residential water demand: a meta analysis. Land Economics 79, 292-308.

Espey, M., Espey, J. \& Shaw, W. (1997). Price elasticity of residential demand for water: a metaanalysis. Water Resources Research, 33(6), 1369-1374.

EWRA. (2008). Egyptian Water \& Wastewater Regulatory Agency Report on the comparative performance of the water and wastewater sector in Egypt and some countries (First Report). Cairo, Egypt.

Fox, C., McIntosh, B.S., and Jeffrey, P. (2009). Classifying Households for Water Demand Forecasting Using Physical Property Characteristics. Land Use Policy 26, 558-568.

Gatersleben, B., Steg, L., Vlek, C. (2002). Measurement and Determinants of Environmentally Significant Consumer Behavior. Environment and Behavior, 34(3), 335-362.

Global Water Partnership. (2011). Towards Integrated Urban Water Management - Perspective Paper, 12.

Grit, R., Jo"rg, L., Steffen, D., \& Osor, G. (2014). Integrated urban water management: development of an adapted management approach. Environmental Earth Science, 73(2), 
709-718.

Gutzler, D. S., Nims J. S. (2005). Interannual variability of water demand and summer climate in Albuquerque, New Mexico. Journal of Applied Meteorology, 44, 1777-1787.

Klein, B., Kenney, D., Lowrey, J., Goemans, C. (2007). Factors influencing residential water demand: a review of the literature. University of Colorado Working paper version 1.12.07.

Larsen, T. A., Hoffmann, S., Truffer, B., \& Maurer, M. (2016). Emerging solutions to the water challenges of an urbanizing world. Science, 352(6288), 928-933.

Loh, M. and Coghlan, P. (2003). Domestic water use study: Perth, Western Australia 1998- 2021. Water Corporations, Perth, Western Australia.

Rozos, E., \& Makropoulos, C. (2012). Assessing the combined benefits of water recycling technologies by modelling the total urban water cycle. Urban Water Journal, 9(1), 1-10.

Sathyamurthi, K. (2013). RESIDENTIAL WATER CONSUMPTION -A Urban Perspective. Sacred Heart Journal of Science and Humanities, 3(1).

Schleich, J., and Hillenbrand, T. (2009). Determinants of residential water demand in Germany. Ecol. Econ., 68, 1756-1769.

Sharma, A. K., Grant, A. L., Grant T., Pamminger F., and Opray L. (2009). Environmental and Economic Assessment of Urban Water Services for a Greenfield Development. Environmental Engineering Science, 26(5).

Speers, A., \& Mitchell, G. (2000). Integrated Urban Water Cycle. In National Conference on Water Sensitive Urban Design - Sustainable Drainage Systems for Urban Areas (pp. 1-11). Melbourne.

Syme, G. J., Shao, Q., Po, M. and Campbell, E. (2004). Predicting and understanding home garden water use. Landscape and Urban Planning, 68, 121-128.

Tischner U. and Schmidt-Bleek F. (1993). Designina goods with MIPS. Frrsrnius Envir, 2, 479-484

Troy, P., \& Holloway, D. (2004). The use of residential water consumption as an urban planning tool : a pilot study in Adelaide. Journal of Environmental Planning and Management, 47(1) (March 2013), 97-114.

Troy, P., Holloway, D., Pullen, S. \& Bunker, R. (2002). Toward sustainability: an Adelaide case study. Troy, P., Holloway, D., Pullen, S. \& Bunker, R. (2002) Toward sustainability: an Adelaide case study.

UN-Habitat. (2008). State of African Cities: A framework for addressing urban challenges in Africa. UN-Habitat, Nairobi.

VEOLIA, \& IFPRI. (2015). The murky future of global water quality.

Wentz, E. A., Gober, P. (2007). Factors influencing water consumption for the city of Phoenix, Arizona. Water Resources Management, 21, 1829-1848

Worthington, A., Hoffman, M. (2008). An empirical survey of residential water demand modelling. Journal of Economic Surveys 22, 842-871.

WWAP. (2016). The United Nations World Water Development Report 2016: Water and Jobs. (United Nations World Water Assessment Programme, Ed.). Paris: UNESCO. 